\title{
A static resistance model and the discontinuous pattern of hydrocarbon accumulation in tight oil reservoirs
}

\author{
Sun Liang ${ }^{*}$, Zou Caineng ${ }^{1}$, Liu Xiaoli ${ }^{2}$, Zhu Rukai $^{1}$ and Wang Xiaoqi ${ }^{1}$ \\ ${ }^{1}$ Research Institute of Petroleum Exploration and Development, PetroChina, Beijing 100083, China \\ ${ }^{2}$ Department of Hydraulic Engineering, Tsinghua University, Beijing 100084, China
}

(C) China University of Petroleum (Beijing) and Springer-Verlag Berlin Heidelberg 2014

\begin{abstract}
In exploration for tight oil, the content and saturation of hydrocarbon in the tight reservoir is a key factor for evaluating the reserve. Therefore, it is necessary to study the geological history of hydrocarbon accumulation and the tight oil charging process. However, kinetic models used for petroleum development are not applicable for petroleum exploration. In this study, a static resistance model is proposed after analyzing resistances in ultra-slow flow in porous media. Using this model, the discontinuous pattern of oil charging is reproduced through incompressible Navier-Stokes equations, the phase field method and the finite element method. This study also explains macroscopic percolation behavior with microscopic flow mechanisms and discusses some issues in ultra-slow flow in a micro/nano pore-throat network. The resistance analysis reveals that capillary resistance and dissipation resistance are dominant factors in the mechanism of oil accumulation in tight reservoirs. Numerical simulations show that pressure thresholds exist and result in discontinuous oil charging. Generally, it is proven that the static model is more applicable than kinetic models in describing oil accumulation in tight reservoirs.
\end{abstract}

Key words: Tight oil, oil charging, wettability, capillary pressure, static resistance, pressure threshold

\section{Introduction}

Tight oil is an unconventional hydrocarbon resource. It is a hydrocarbon accumulation stored in an ultra-lowpermeability reservoir which is usually near or sandwiched by source rocks (Jia et al, 2012). Following the shale gas revolution in North America, tight oil has become another focus for unconventional hydrocarbon resources. In 2012, the technologically recoverable reserves of tight oil in the United States are approximately 4.53 billion tons (Conti et al, 2012). It shows great potential for the future exploration and development.

A tight oil reservoir usually has ultra-low porosity $(\Phi \leq 10 \%)$ and permeability $(k \leq 0.1-1 \mathrm{mD})$. In exploration and development of tight oil, the content and saturation of hydrocarbons in a tight reservoir is a key factor for evaluating the reserve and estimating ultimate recovery. However, the accumulation and migration mechanisms of fluid in tight reservoirs are more complex than in conventional reservoirs. Many studies of great value have been undertaken in the last few decades. In the early stages, research focused on the nonlinear percolation behaviors of fluid in tight reservoirs, e.g., experiments on threshold pressure gradient (Miller and

*Corresponding author. email: sunliang0315@gmail.com Received September 22, 2013
Low, 1963), factor analysis (Olsen, 1965), mathematical model descriptions (Swartzendruber, 1962a; 1962b), etc. The boundary layer is believed to be the main reason for the nonlinear percolation behaviors (Sakiadis, 1961). This theory states that there is a fluid layer near the fluid-solid interface due to the adhesive forces. Fluid in this layer is much more difficult to move than that outside the layer. The thickness of the layer reduces with an increase of the pressure gradient. Boundary layer theory may be a good mechanism for understanding nonlinear percolation behaviors if the fluid flow has certain speed. However, for ultra-slow flow, there is no sophisticated theory.

In recent years, with the development of observation techniques, great progress has been achieved in describing the micro structures of tight reservoir and shale. Reports in this field cover many aspects of the pore-throat network, e.g., size, distribution, connectivity, classification, evolution, etc. (Jarvie et al, 2007; Chalmers and Bustin, 2008; Loucks et al, 2009; Ross and Bustin, 2009; Zou, 2012; Zou et al, 2013c). Many types of equipment have been applied, e.g., 3D X-Ray CT (Golab et al, 2010; Bai et al, 2013), SEM (Sondergeld et al, 2010), etc. Based on the observed micro structures, the mechanisms of fluid migration and accumulation at the micro level have also been investigated (Schnaar and Brusseau, 2005; Liang et al, 2008; Javadpour, 2009; Slatt and O'Brien, 2011; Schmutz et al, 2012; Weszka et al, 2012). 
Studies found that capillary effects are significant in the fluid migration in tight reservoirs (Zou et al, 2013c). Surface tension and wettability are the two main factors causing capillary pressure. Research on surface tension focuses on its significance and factors under natural reservoir conditions (Badakhshan and Bakes, 1990; Demond and Roberts, 1991; Cai et al, 1996; Zuo and Stenby, 1998; Ye et al, 2011). Research on wettability has been more focused on the process of water displacing oil (Morrow, 1990; Jadhunandan and Morrow, 1995; Liu et al, 2012).

However, most of the studies are applicable to the petroleum development stage rather than exploration (Deng et al, 2013; Yao et al, 2013). Only a few studies have been performed focusing on the petroleum accumulation stage. Based on comprehensive geological investigations, these studies present some definitions and descriptions of sedimentary and tectonic characteristics of unconventional reservoirs (Guo et al, 2012; Kuang et al, 2012; Liu et al, 2013; Zou et al, 2013a; 2013b). Due to the very significant difference of the time scales between the accumulation and development stages, mechanisms suggested for petroleum development research are not applicable to accumulation studies.

In this study, resistance during the tight oil charging period is analyzed and a static resistance model is proposed. In this model, kinetic resistance is ignored because the charging process is ultra-slow. Then the discontinuous oil charging process is investigated using incompressible NavierStokes equations, the phase field method and the finite element method. Numerical simulations of oil displacing water reproduce the phenomena of threshold pressure and retained water. Although there is still much work needed to complete the proposed model, it is believed that the static model is more applicable than the kinetic model to describe the tight oil charging process.

\section{Resistance analysis of fluid flow in porous media}

\subsection{Surface tension and wettability}

Surface tension is a contractive tendency of liquid surfaces that can resist an external force. The cohesive forces between liquid molecules are responsible for the phenomenon of surface tension. If the surface is also the interface between two immiscible liquids, it is sometimes called interfacial tension. The molecules on the surface have different cohesive forces from the two liquid phases; therefore the surface usually bends due to the unbalanced forces. Free energy is stored in this curved surface and its unit is $J / \mathrm{m}^{2}(\mathrm{~N} / \mathrm{m}$ is also used).

Wettability is the ability of a liquid to maintain contact with a solid surface due to the adhesive forces between liquid and solid molecules. The degree of wettability is determined by the difference between adhesive and cohesive forces. Usually the contact angle between the liquid and solid surfaces is used to measure wettability. In two phase flow in porous media, one liquid, called the wetting phase, has the priority to maintain contact with the pore surface due to the difference of wetting ability. The contact angle of the wetting phase is usually between $0^{\circ}$ and $90^{\circ}$.

Surface forces and wettability are also responsible for other related effects, including so-called capillary effects, especially when the fluid channels are small. On the curved surface of two immiscible liquids, the total force is unbalanced due to wettability. This unbalanced force, carried by the surface tension, results in the capillary pressure. The capillary pressure is influenced by the surface tension, wettability and capillary size, i.e.,

$$
p_{\mathrm{c}}=\frac{2 \sigma \cos \theta}{r}
$$

where, $P_{\mathrm{c}}$ is the capillary pressure $(\mathrm{Pa}) ; \sigma$ is the surface tension $(\mathrm{N} / \mathrm{m}) ; \theta$ is the contact angle $\left(^{\circ}\right) ; r$ is the capillary radius $(\mathrm{m})$.

From Eq. (1), it can be found that there is no capillary pressure $\left(P_{\mathrm{c}}=0\right)$ if there is no surface tension $(\sigma=0)$ or wettability $\left(\theta=90^{\circ}\right)$. If the size of the capillary is large $(r \gg 2 \sigma \cos \theta)$, the capillary pressure is neglected $\left(P_{\mathrm{c}} \approx 0\right)$. For convenience, it is assumed that the fluids have proper surface tension and wettability and the size of pore-throat network is comparably small. Under this circumstance, the capillary effect is significant. In the process of oil charging in tight reservoirs, capillary pressure is the main resistant force. In conventional petroleum geology, the resistance of a drop of oil migrating from a pore into a throat can be described as:

$$
\Delta p_{\mathrm{c}}=2 \sigma \cos \theta\left(\frac{1}{r_{\text {throat }}}-\frac{1}{r_{\text {pore }}}\right)
$$

where, $\Delta p_{\mathrm{c}}(\mathrm{Pa})$ is the difference between the capillary pressure on the oil-water interface in the throat and that on the oil-water interface in the pore. It should be noticed that Eq. (2) can only describe the capillary pressure difference on an oil drop which has two oil-water interfaces. In conventional reservoirs, $\Delta p_{\mathrm{c}}$ is usually compared with the buoyancy to evaluate the mobility of oil. However, in unconventional hydrocarbon accumulation, it is not believed that movement of individual drops is the main form of oil migration. Therefore, Eq. (2) is not appropriate to evaluate the migration resistance. Instead, fluid dynamics and computational methods are adopted to analyze the significant effect of surface tension, wettability and pore-throat network on hydrocarbon migration in tight reservoirs.

\subsection{Macro percolation behaviors}

In poromechanics, the Darcy's equation is commonly used to describe the macro behaviors of fluid flow in porous media, i.e.,

$$
\mathbf{v}=-\frac{\mathbf{k}}{\mu} \nabla P
$$

where, $\mathbf{v}$ is the percolation velocity of the fluid flow $(\mathrm{m} / \mathrm{s}) ; \mathbf{k}$ is the permeability of the porous media $\left(\mathrm{m}^{2}\right) ; \mu$ is the dynamic viscosity of the fluid (Pas); $P$ is the fluid pressure (Pa). $\nabla P$ is 
the gradient of the pressure $(\mathrm{Pa} / \mathrm{m})$. Usually, the percolation experiments are performed in the laboratory and the pressure gradient is defined as:

$$
\nabla P=\frac{\Delta P}{\Delta L}
$$

where, $\Delta P$ is the pressure difference between the two ends of the sample $(\mathrm{Pa})$ and $\Delta L$ is the sample length $(\mathrm{m})$. In fact, Darcy's equation can be simplified and derived from NavierStokes equations under certain circumstances (Kozeny, 1927).

Based on Eqs. (3) and (4), the Darcy's equation can be understood in another way, i.e.,

$$
\Delta P=-\frac{\mu \mathbf{v}}{\mathbf{k}} \Delta L
$$

Eq. (5) shows the resistance when fluid flows through a porous media. Obviously, the resistance is proportional to viscosity, percolation velocity and flow distance. It is inversely proportional to permeability. For a specific sample, the resistance of the fluid flow increases linearly with the percolation velocity. However, it has been proved that this relationship is only valid when the percolation velocity is in a certain range (Bear, 1972). Generally, laminar flow is one assumption of the Darcy's equation. The Reynolds number is usually used to check the applicability and it should satisfy Eq. (6) below for laminar flow,

$$
R e=\frac{\mathbf{v} d}{v} \leq 1-10
$$

where, $\mathbf{v}$ is the percolation velocity $(\mathrm{m} / \mathrm{s}) ; d$ is the characteristic size of the porous media $(\mathrm{m}) ; v$ is the kinetic viscosity $\left(\mathrm{m}^{2} / \mathrm{s}\right)$.

However, there have been for a long time arguments about the lower limit of the Darcy equation's applicability. A compromised solution is using a nonlinear equation with a mobilizing pressure gradient to describe the percolation behavior in low-permeable media (Fig. 1). The percolation curve includes three stages. In Zone I, the curve coincides with the $\mathrm{X}$-axis and no through-percolation occurs. In Zone II, the curve is nonlinear. In Zone III, the curve can be treated as linear (or quasi-linear). As the transition point between Zone I and Zone II, $a$ is usually called the threshold pressure

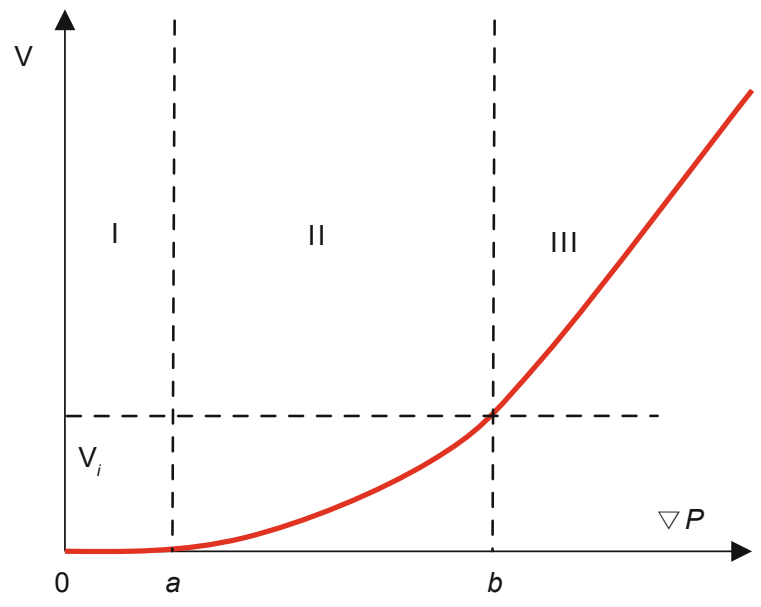

Fig. 1 Nonlinear percolation behavior in a tight reservoir gradient. As the transition point between Zone II and Zone III, $b$ is usually called critical pressure gradient.

As shown in Section 1, a lot of work has been reported on the nonlinear percolation behavior with a threshold pressure gradient. However, Zone III is always considered as the main part in these mechanisms because most of the research is applied to the stage of petroleum development in which certain percolation velocity is required. There are few studies on quantitative description of the mechanisms of Zone I and II.

Different from the percolation behavior during petroleum development, the percolation during the stage of hydrocarbon accumulation is ultra-slow. It is believed that Zone I and II (i.e., the curve below $\mathrm{V}_{i}$ in Fig. 1) is the dominant mechanism controlling oil charging in tight reservoirs. In the next section, a static resistance model is proposed to describe the mechanism of Zone I and Zone II.

\subsection{Static resistance}

Generally, the total resistance to fluid flow in porous media includes two parts, i.e., static resistance and kinetic resistance. Kinetic resistance is very common in almost all the material movements. Kinetic resistance usually increases with the speed of movement. For example, in Darcy's equation (Eq. (3)), the resistance $(\nabla P)$ increases linearly with the average fluid speed. Another example is that the resistance of high-speed flow (turbulence) is proportional to the square of velocity.

Static resistance plays an important role especially when the flow is very slow or even before it starts to move. Capillary resistance is a part of static resistance. It should be noticed that capillary resistance only exists in two (multiple) phase flow. Another important part of static resistance is called dissipation resistance. Dissipation resistance includes all the resistance related to the area of fluid-solid interface. Various physical and chemical interactions between the solid and fluid may contribute to dissipation resistance, for example, the adhesive forces and absorption. Obviously, dissipation resistance increases with the specific surface area of the pore-throat network and the distance of the go-through paths for the fluid. Therefore, it can be inferred that dissipation resistance is much larger in a nano-pore network than in a micro-pore network. Dissipation resistance is responsible for the reduction of the pressure gradient in a static condition. Fig. 2 shows the schematic of resistances on fluid flow in porous media.

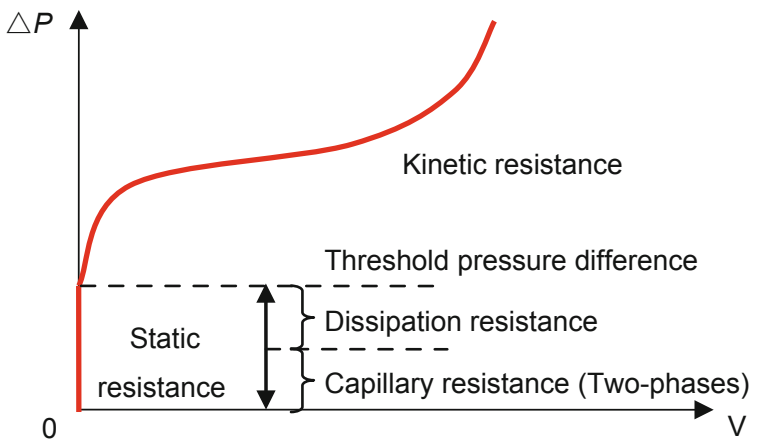

Fig. 2 Resistance to fluid flow in porous media 
Generally, the total resistance force on the fluid is shown below,

$$
\Delta P=\Delta P_{\mathrm{c}}+\int_{L} \nabla P_{\mathrm{d}} \mathrm{d} l+\Delta P_{\mathrm{k}}
$$

where, $\Delta P_{\mathrm{c}}$ is the capillary pressure $(\mathrm{Pa}) ; \nabla P_{\mathrm{d}}$ is the dissipation pressure gradient $(\mathrm{Pa} / \mathrm{m}) ; \Delta P_{\mathrm{k}}$ is the kinetic resistance $(\mathrm{Pa})$ related to percolation velocity (e.g., Eq. (5)). In the static resistance model, $\Delta P_{\mathrm{k}}$ is assumed to be zero and therefore Eq. (7) is simplified as:

$$
\Delta P=\Delta P_{\mathrm{c}}+\int_{L} \nabla P_{\mathrm{d}} \mathrm{d} l
$$

\subsection{Pore-throat network}

The pore-throat network in a porous medium is the bridge connecting the micro and macro behaviors. To some extent, the macro percolation behaviors are the average of an enormous number of micro flows in a complex porethroat network. In the early stage of percolation research, it was not possible to examine the micro structure and the studies of micro flows were not well performed. In another aspect, the macro average was explicit and its accuracy was accepted by engineers. Recently, many micro methods

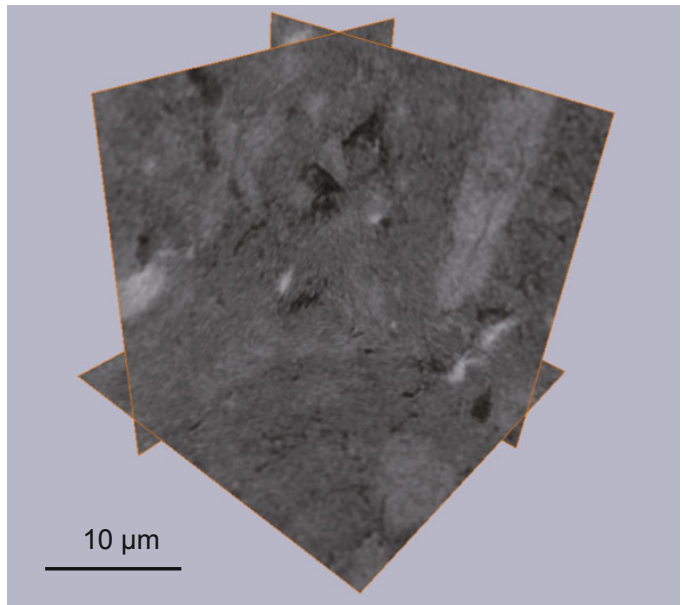

(a)

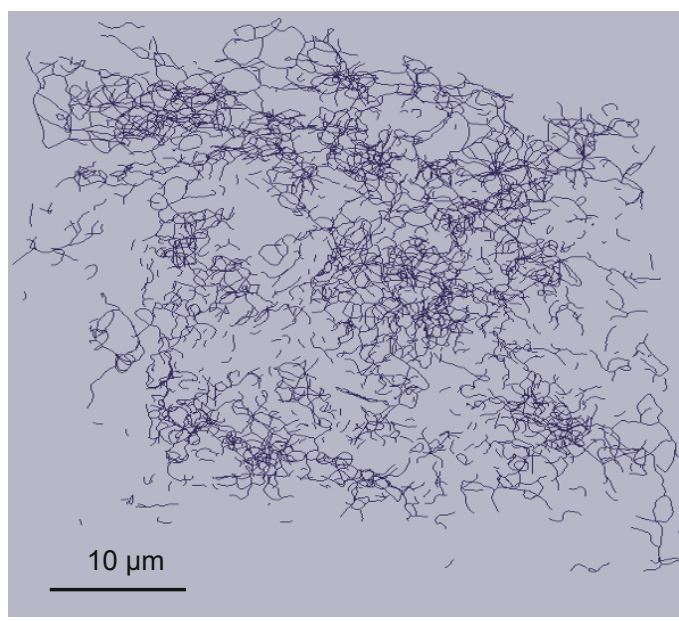

(c) including molecular dynamics have been applied to studying percolation behaviors. The development of observation equipment also helps to exam the micro structure of a sample.

With the help of CT scanners and image processing tools, it can be found, unsurprisingly, that the complexity of the pore-throat network is beyond imagination. Fig. 3 shows the $\mathrm{CT}$ images and processed results of a tight sandstone sample. The range of interest (ROI) is $30 \mu \mathrm{m} \times 30 \mu \mathrm{m} \times$ $30 \mu \mathrm{m}$. Pores and throats distribute randomly in size and location. Connectivity of these pores and throats is verified (AVIZO, 2014). Then a numerical simulation is performed based on the obtained connectivity. It can be found that the fluid flow in the ROI is heterogeneous. Most of the locally connected pores are not globally connected in the ROI. Fluid only goes through some unpredictable paths. Obviously, the heterogeneity and non-homogeneity must be considered in investigating the micro mechanism. Statistical physics is the only way to understand such complex system.

This section aims to demonstrate the significance of quantifying pore-throat networks. It plays an important role in reproducing the macro percolation behaviors using micro mechanisms. It is the only way to upscale the micro mechanism by combining a quantitatively described porethroat network.

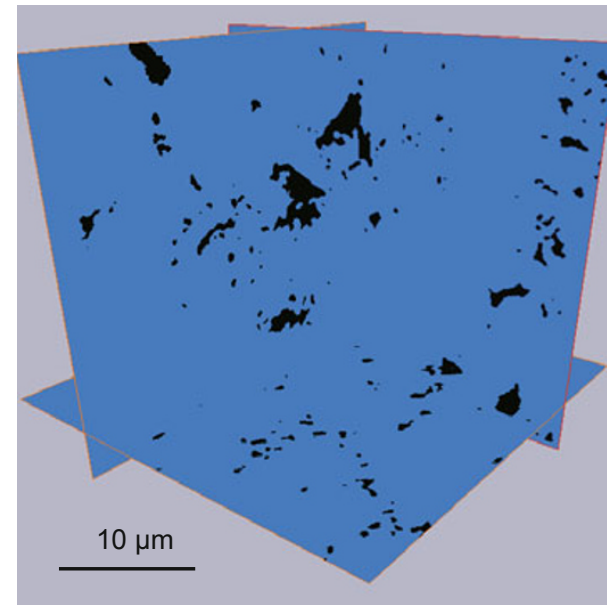

(b)

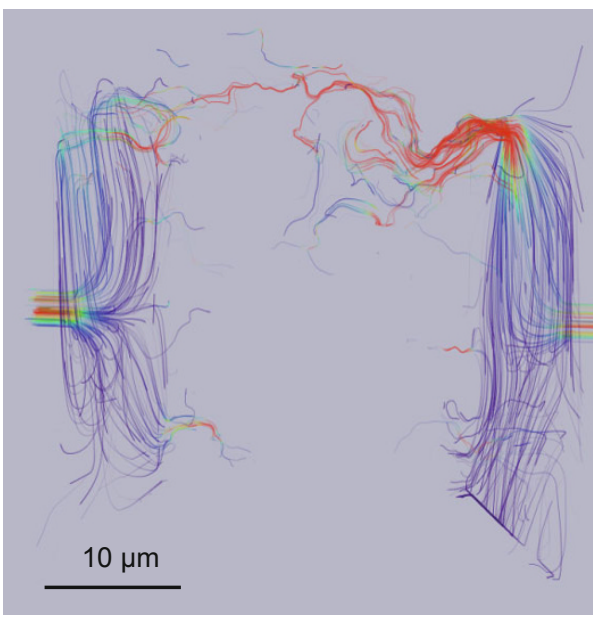

(d)

Fig. 3 Pore-throat network observed with a CT scanner and post-processed by other tools: (a) original CT image; (b) segmentation of pores and matrix; (c) connectivity of pores; (d) numerical simulation of fluid flow in the sample 


\subsection{Explanation of nonlinear percolation behavior}

Because fluid flows through the complex pore-throat network in rock, the flow path is a space curve rather than a straight line. Therefore, the length of a sample $(\Delta L)$ is the nominal migration distance of the fluid. The real migration distance is much longer. Thus, the concept of pressure gradient in a laboratory test is a macro average. From Eq. (4), either a larger pressure difference or a shorter migration distance may deduce a large pressure gradient. Without considering the micro structure of the pore-throat network, important information may be overlooked.

In this study, the macro percolation behaviors are explained through the micro mechanism presented previously. For demonstration, a schematic pore-throat network is drawn in Fig. 4 and fluid flows through it from the left to the right.

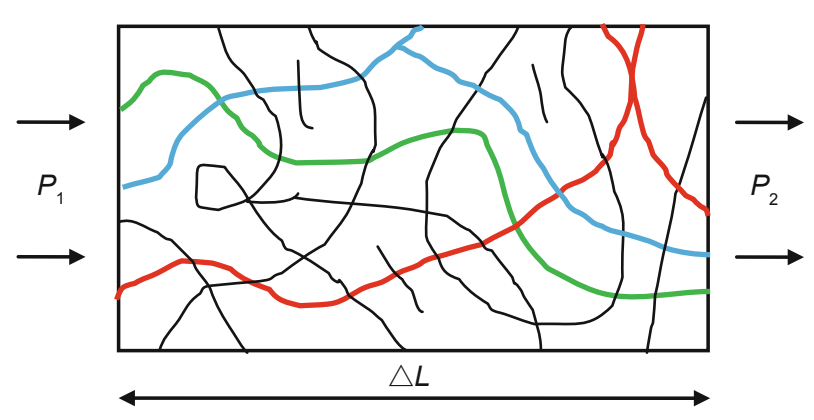

Fig. 4 Percolation in a rock sample (The green line is the easiest for fluid to go through; the blue one is more difficult; the red line is very hard to go through)

Of all the possible paths, there is one where a minimal pressure threshold is needed (as shown in Eq. (8)), for example, the green path in Fig. 4. It is assumed that the pressure difference is $\Delta P_{a}$ and the real length of the green path is $\Delta L_{\text {green }}$. The nominal pressure gradient is $a=\Delta P_{a} / \Delta L$ and it is called the threshold pressure gradient. However, the real pressure gradient should be $a^{\prime}=\Delta P_{a} / \Delta L_{\text {green. }}$. Before the green path is broken through, the macro percolation curve remains in Zone I.

After the pressure difference reaches $\Delta P_{a}$, there is continuous fluid flux through the sample and the percolation mode enters Zone II. With the increase of pressure difference, more paths are broken through, for example, the blue path in Fig. 4. Because more paths are broken through, the fluid flux increases. Thus, the percolation curve increases nonlinearly.

When the pressure difference reaches $\Delta P_{b}$, the hardest path in the sample is broken through, for example, the red path. At this moment, the nominal pressure gradient is $b=\Delta P_{b} / \Delta L$, i.e., the critical pressure gradient. Different from $a^{\prime}$, the real critical pressure gradient cannot be defined, because the lengths of paths are varied. After $\Delta P_{b}$, the percolation behavior enters Zone III. Because there are no more paths that can be broken through, the fluid flux increases linearly with the increase of pressure difference.

In summary, the proposed static resistance model can explain the macro percolation behaviors logically. The typical percolation behavior shown in Fig. 1 is highly related to the structure of the pore-throat network. A sample with higher compaction, smaller average throat size and a complex network presents highly nonlinear behaviors. It is not surprising that samples from the same field present varied curves considering the heterogeneity.

\section{Applicability}

In the previous section, a micro mechanism is proposed to reproduce the macro percolation behaviors. Admittedly, these analyses are based on certain assumptions and applications are only applicable under specific conditions. Some of the assumptions and applicability are discussed in this section.

\subsection{Ultra slow flow}

In classical research on percolation, the pressure gradient is the most importance index to evaluate the permeability of a rock sample. It represents the hydraulic loss of pressure proportional to the average fluid velocity. As kinetic resistance, it is not applicable when fluid speed is very low, like the Darcy's equation. From the previous analysis, static resistance dominates the ultra-slow fluid flow in a tight reservoir. A general expression has been given in Eq. (8). More specific equations for pressure gradient based on dissipation resistance, rather than percolation velocity, will be established in future.

\subsection{Applicable scale}

Mechanism of micro flow is always constrained with the scale of the pore-throat size. Corresponding to the previous study, the applicable scale of the theory of capillary resistance should be approximately larger than the scale below which molecular dynamics is believed to be the dominant mechanism. On the other side, the capillary effect can be omitted if the pore-throat size is large enough. Therefore, it is empirically suggested that the mechanism of capillary effect is considered when the dominating pore-throat size is between $10 \mathrm{~nm}-100 \mu \mathrm{m}$. This covers the range in which the pore-throat sizes of unconventional reservoirs distribute. For example, $80 \%-90 \%$ of the pores and throats of the tight sandstone reservoirs in the Ordos Basin have radii between $10 \mathrm{~nm}$ and $1 \mu \mathrm{m}$ (Zou et al, 2013d).

\subsection{Existence of capillary effect}

Two phase (oil displacing water) flow will be used to demonstrate the capillary effect. In the process of oil displacing water, surface tension and wettability are an unfavorable combination. It can be inferred that the process of water displacing oil is much easier if water is still the wetting phase. There is even no capillary effect in single phase flow. However, it is believed that there is not just pure fluid in porous media. There is always some gas (methane) in a highly saturated rock layer. These isolated gas bubbles cause the Jamin effect which contributes to the total static resistance (Jamin, 1860). Admittedly, it is difficult to distinguish such capillary effects from the dissipation resistance before more studies are performed on the latter. Thus, only the simple situation of two phase flow is considered in this paper. 


\subsection{Properties of pore-throat network}

Although the properties of the pore-throat network play an important role in the micro and macro percolation behaviors, sufficient studies have not yet been performed. Current research is qualitative rather than quantitative. In this work, only elementary and abstract network models are considered. In the future, more properties of the network will be quantitatively investigated and considered as factors influencing micro flow mechanisms.

\subsection{Dissipation resistance and pressure gradient}

From the previous analysis, dissipation resistance causes a reduction of the pressure gradient. Many factors influence the dissipation resistance, for example, properties of the pore-throat network and interaction between the fluid and solid surfaces. In this paper, dissipation resistance has not been investigated. Therefore, the second term in Eq. (8) is not discussed. It will be examined in future work.

\section{Discontinuous oil charging}

In the previous section, the proposed static resistance model states that threshold pressures should be overcome to continue oil charging. It implies that the oil charging process is discontinuous even if it is assumed that driving force increases continuously. In this section, finite element analysis (COMSOL, 2013) is conducted to reproduce this process and explain some phenomena.

\subsection{Basic models and validation}

In this section, three 3D models of capillaries are established to validate the numerical algorithm.

The models describe three ideal and typical capillary channels (Fig. 5). In Model (a), the channel length is $10 \mu \mathrm{m}$ and the radius is $1 \mu \mathrm{m}$. The initial liquid interface is in the middle of the channel (the upper part is water and the lower part is oil). In Model (b), the total channel length is $10 \mu \mathrm{m}$ (5 $\mu \mathrm{m}$ for each part). The radius of the lower part is $1 \mu \mathrm{m}$ and the radius of the upper part is $0.5 \mu \mathrm{m}$. The initial liquid is water in the upper part of the fine channel and the lower part of the coarse channel. The middle part is oil. In Model (c), the total length of the channel is $7.5 \mu \mathrm{m}(2.5 \mu \mathrm{m}$ for the upper, middle and lower parts, respectively). The radius of the lower part is $1 \mu \mathrm{m}$ and the radius of the upper part is $0.5 \mu \mathrm{m}$. The initial liquid in the half-space is oil and other parts are water. The numerical models adopt mapped prismatic meshes and there are 1,456,2,870 and 2,280 elements respectively for the three models. In all the three models, the fluid flows from the bottom to the top. The channel walls are assumed to be water-wetted. The properties of the fluids and other parameters are shown in Table 1.

After the numerical models are established, finite element analyses are conducted to validate these basic models. Fig. 6 shows the simulation results of Model (a) by presenting the oil-water interface on a vertical axisymmetric section. This simulation compares 9 scenarios in which the pressure difference between the inflow and outflow ends varies from 0 to $0.04 \mathrm{MPa}$ with an interval of $0.005 \mathrm{MPa}$. It can be found that the oil-water interface locates at different places at the

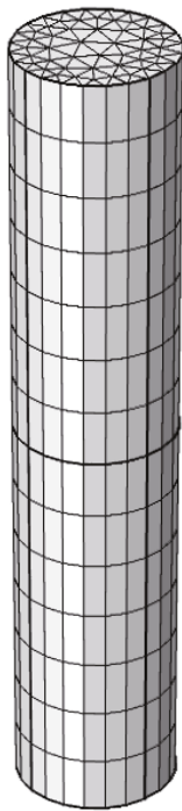

(a)

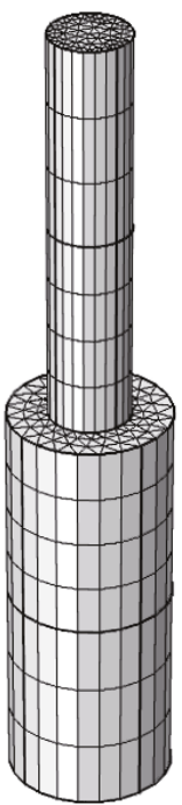

(b)

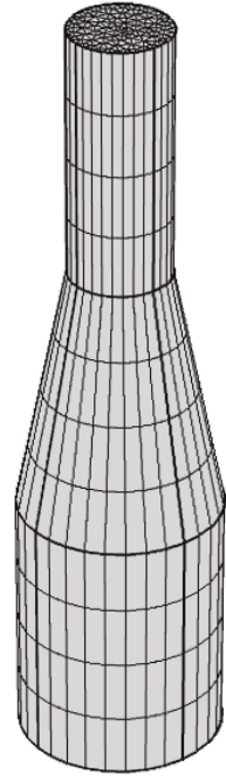

(c)
Fig. 5 Models of capillaries

Table 1 Properties of the fluids and other parameters

\begin{tabular}{ccccc}
\hline & $\begin{array}{c}\text { Density } \\
\mathrm{kg} / \mathrm{m}^{3}\end{array}$ & $\begin{array}{c}\text { Dynamic } \\
\text { viscosity, } \mathrm{Pa} \cdot \mathrm{s}\end{array}$ & $\begin{array}{c}\text { Oil-water surface } \\
\text { tension, } \mathrm{N} / \mathrm{m}\end{array}$ & $\begin{array}{c}\text { Contact angle } \\
\text { of water, rad }\end{array}$ \\
\hline Oil & 838 & $3.2 \times 10^{-3}$ & 0.025 & $\pi / 3$ \\
Water & 1000 & $1.003 \times 10^{-3}$ & & \\
\hline
\end{tabular}

same simulation time. When the pressure difference is lower than $0.025 \mathrm{MPa}$, the fluid moves toward the oil side due to the capillary pressure. When the pressure difference increases up to $0.025 \mathrm{MPa}$, the oil-water interface begins to move toward the water. The threshold pressure difference is equal to the capillary pressure which can be analytically calculated through Eq. (1). It should also be noticed that the fluid velocity and the bending degree of the interface both increase with the pressure difference. Therefore, the speed of the oil charging process does not increase linearly with an increase of the pressure difference, although rapid oil charging is not currently the focus of this research.

The pattern of oil-water displacement (Fig. 7) in Model (b) is similar to Model (a). When the pressure difference increases up to $0.05 \mathrm{MPa}$, the capillary resistance is overcome. This result is consistent with the calculation of Eq. (1). The simulation results (Fig. 8) of Model (c) is similar to Model (b). However, the capillary resistance in Model (c) becomes smaller during the upward movement of the oil column. Therefore, it is much easier for oil to displace water in Model (c) than Model (b). These two models to some extent demonstrate that a smooth channel is an asset for fluid migration.

The change of capillary pressure with the capillary size is also validated in this section. Fig. 9 shows the different positions of oil-water interface in different capillaries. The simulation result is also consistent with the capillary theory, therefore not detailed. 

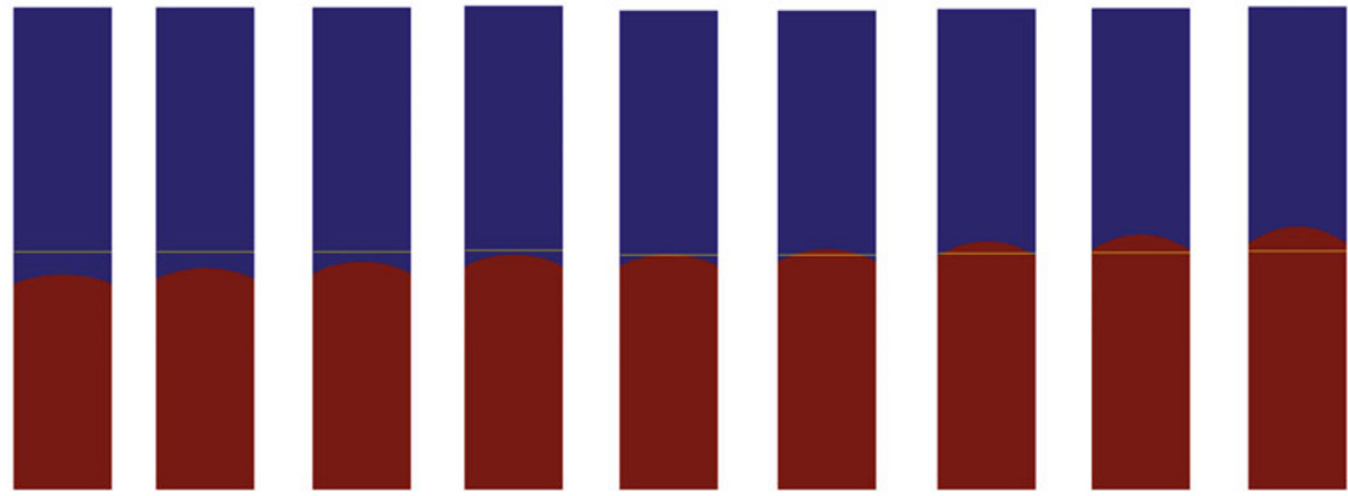

Fig. 6 Oil-water interface in a uniform capillary under varied pressure difference $(t=5 \mu \mathrm{s}, r=1 \mu \mathrm{m}, \Delta P=0-0.04 \mathrm{MPa}$, interval=0.005 $\mathrm{MPa})$
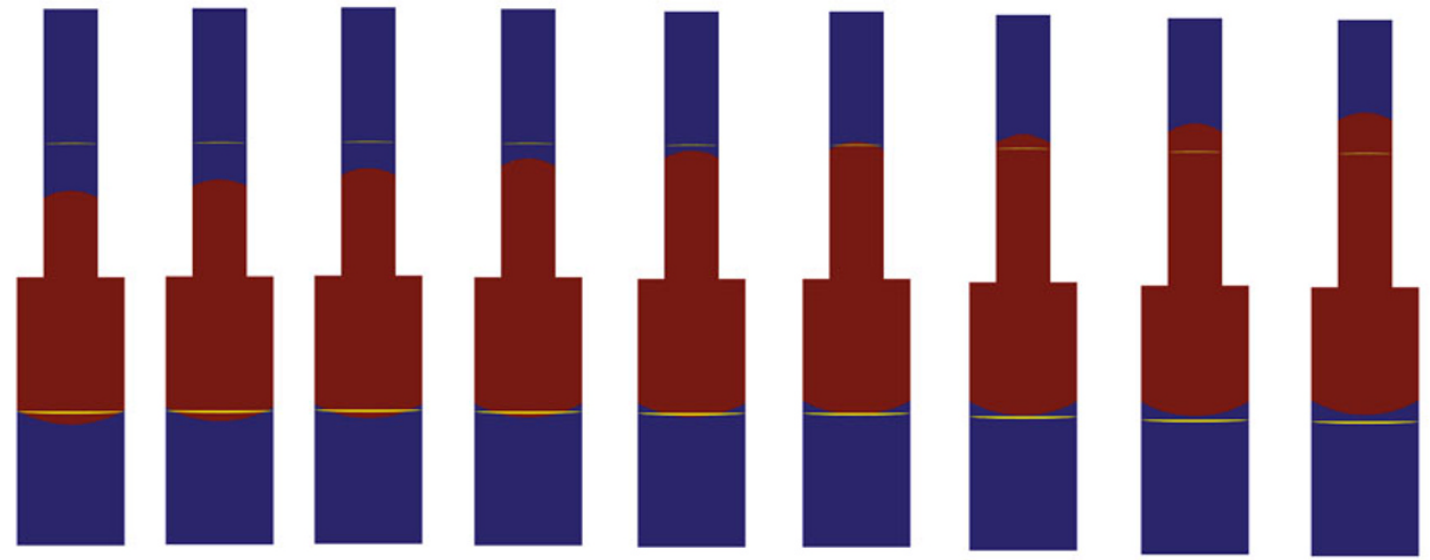

Fig. 7 Oil-water interface in a stepped capillary under varied pressure differences $\left(t=5 \mu \mathrm{s}, r_{1}=1 \mu \mathrm{m}, r_{2}=0.5 \mu \mathrm{m}, \Delta P=0-0.08 \mathrm{MPa}\right.$, interval=0.01 MPa)
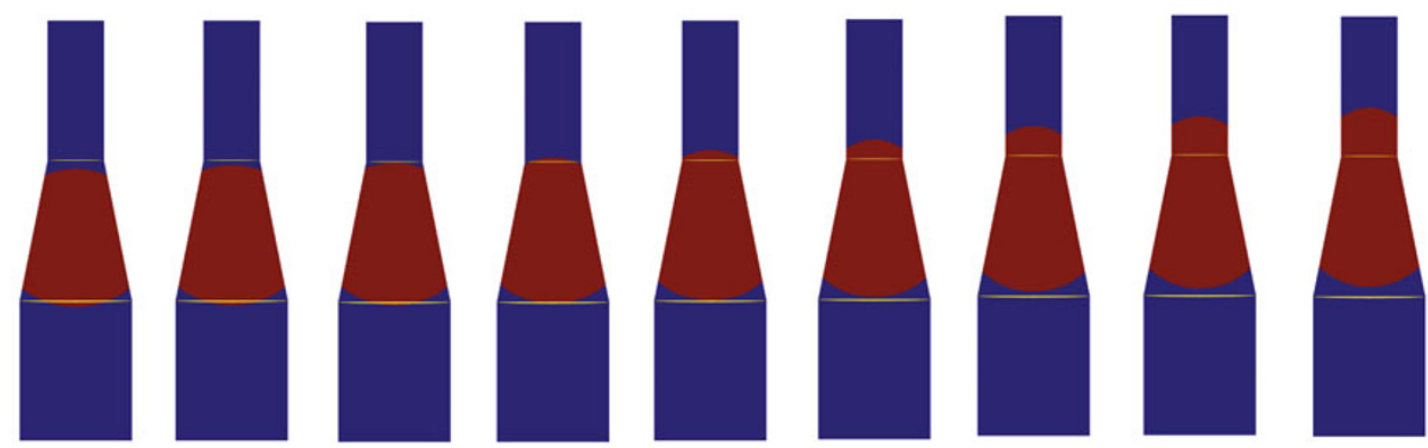

Fig. 8 Oil-water interface in a convergent capillary under varied pressure difference $\left(t=5 \mu \mathrm{s}, r_{1}=1 \mu \mathrm{m}, r_{2}=0.5 \mu \mathrm{m}, \Delta P=0-0.04 \mathrm{MPa}\right.$, interval=0.005 MPa)

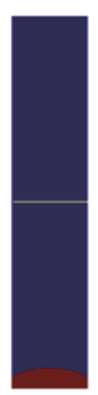

$r=50 \mathrm{~nm}$

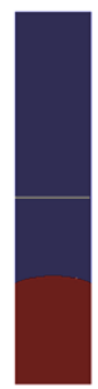

$r=100 \mathrm{~nm}$

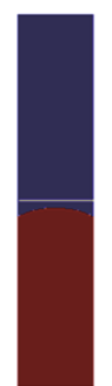

$r=500 \mathrm{~nm}$

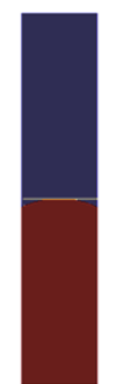

$r=1000 \mathrm{~nm}$

Fig. 9 Oil-water interface in capillary channels with different sizes $(t=1 \mu \mathrm{s}, \Delta P=0.01 \mathrm{MPa})$ 


\subsection{Oil charging in a single channel}

In unconventional petroleum geology, a popular assumption is that hydrocarbons migrate into the reservoir after it becomes tight. The driving force for the migration is mainly the overpressure from hydrocarbon generation. It is believed that a process that oil gradually displaces the pore water occurs during the hydrocarbon accumulation. In the following two sections, numerical simulations are performed to reproduce the discontinuous process of oil charging.

First, a single channel is established to model the oil charging process. This model (Fig. 10) includes general channels, a pore and narrower throats. Through the simulation of this model, thresholds of pressure difference mobilizing the displacing process can be observed. The geometries, meshes, fluid properties, boundary conditions, etc., are similar to those in the previous section.

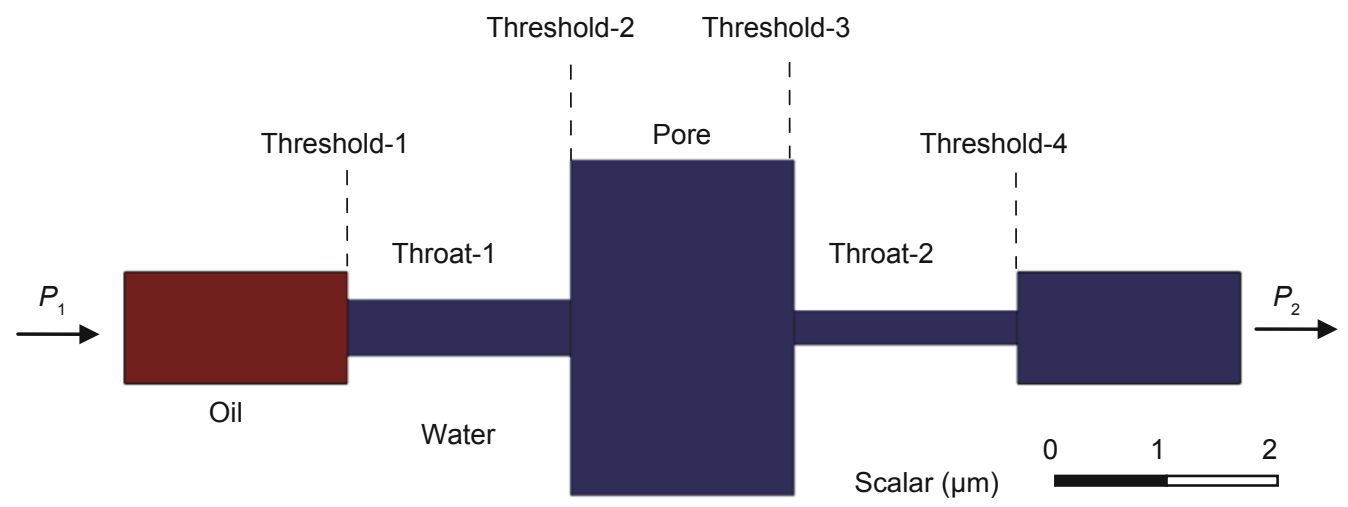

Fig. 10 The model of oil charging in a single channel

In the simulation, the driving force, i.e., the pressure difference between the two ends $\left(\triangle P=P_{1}-P_{2}\right)$, is increased step by step. It can be found that there are four pressure thresholds to break in order to complete the oil charging process (Fig. 11). Threshold-1 comes from the entry of Throat- 1 where the breaking pressure is about $0.05 \mathrm{MPa}$. The mechanism has been explained in Model (a) in the previous section. Threshold- 2 comes from the exit of Throat- 1 to the pore. Due to the surface tension and wettability, the curvature of the oil-water interface increases during the oil charging. Therefore, greater pressure resistance forms until the curved interface cannot sustain the pressure and changes shape. In this model, the breaking pressure for Threshold-2 is about 0.075 MPa. Similar to Threshold-1, Threshold-3 comes from the entry of Throat- 2 and the breaking pressure is about 0.083 MPa. Likewise, Threshold-4 comes from the exit of Throat-2 and the breaking pressure is about $0.099 \mathrm{MPa}$.

This simulation explains the phenomenon that there is a threshold pressure difference driving the oil charging process to start. From this simulation, it can also be found that the oil charging process is discontinuous. With the increase of the pressure difference (driving force), oil migrates into smaller throats and moves further. Oil saturation is simulated in this model. In the oil charging process, the oil cannot displace all the water in pores. The quantity of retained water is influenced by the structure of the pore-throat network. The channel in Fig. 12 has less retained water than that in Fig. 11. This feature provides a possible explanation for oil saturation, however, it will not be detailed in the current presentation.

\subsection{Oil charging in a pore-throat network}

In this section, simulations are performed based on a pore-throat network model (Fig. 13) which in some extent reproduces the macro percolation behaviors of fluid in porous (a)

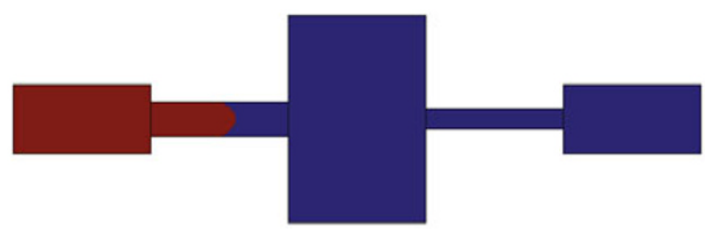

(b)

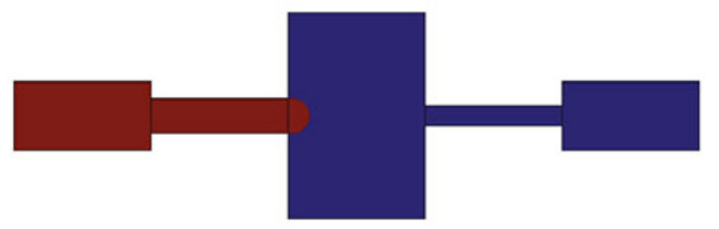

(c)

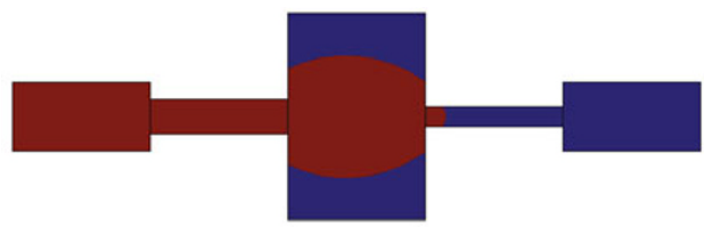

(d)

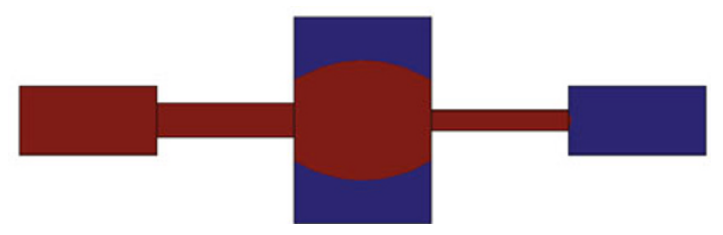

Fig. 11 The process of pressure threshold in the oil charging process in a single channel

media. In this network, there are two flow entrances and three exits. The geometries, meshes, fluid properties, boundary conditions, etc., are similar to those in the previous section.

At the beginning of the simulation, the entries $\left(P_{1-1}\right.$ and $\left.P_{1-2}\right)$ and the exits $\left(P_{2-1}, P_{2-2}\right.$ and $\left.P_{2-3}\right)$ have the same pressure, respectively. Then, the pressure differences between the 


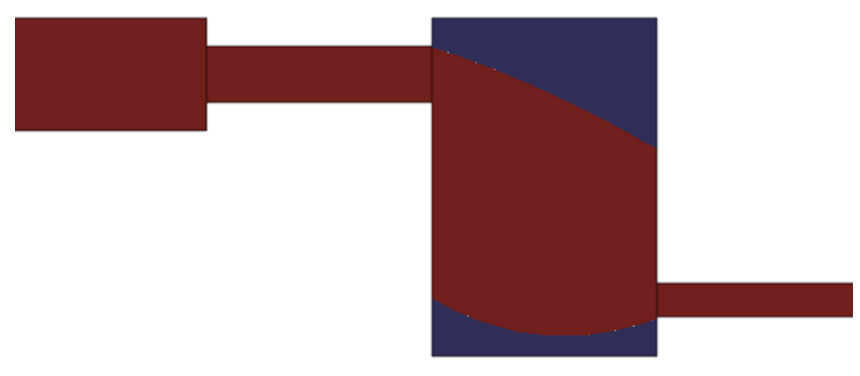

Fig. 12 Pore water retention in the oil charging process

entries and exits are increased. Like the previous simulations, the oil overcomes the capillary resistance and starts to displace the water when the pressure difference is $0.025 \mathrm{MPa}$ (Fig. 14(a)). When the pressure difference is increased to 0.05 $\mathrm{MPa}$, the oil breaks the path from $P_{1-1}$ to $P_{2-1}$ (Fig. 14(b)). When the pressure difference is increased to $0.07 \mathrm{MPa}$, the

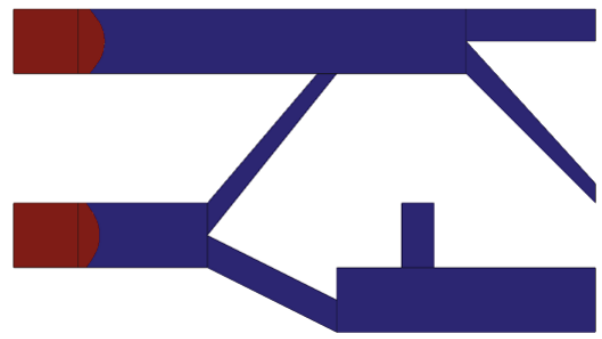

(a) $\triangle P=0.025 \mathrm{MPa}$

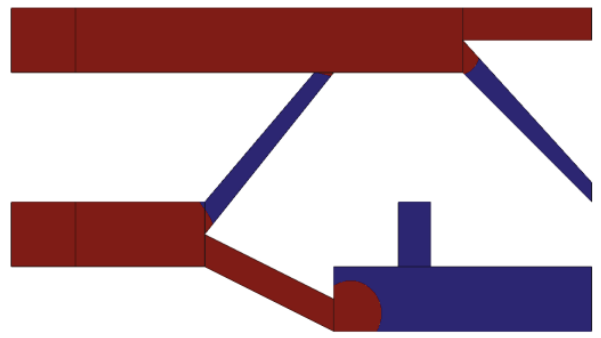

(c) $\Delta P=0.07 \mathrm{MPa}$

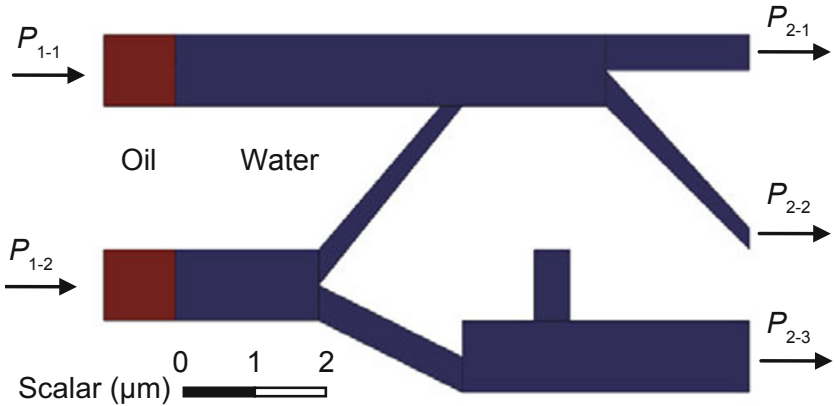

Fig. 13 The model of oil charging in a pore-throat network

path from $P_{1-2}$ to $P_{2-3}$ is broken through (Fig. 14(c)). With the continuous increase of the pressure difference, the path from $P_{1-1}$ to $P_{2-2}$ is finally broken through when $\Delta P$ is equal to 0.12 MPa (Fig. 14(d)). However, it is unexpected that the path from $P_{1-2}$ to $P_{2-3}$ cannot be broken through no matter how high the pressure difference is.

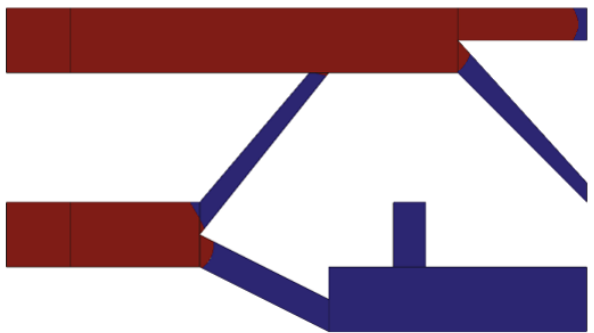

(b) $\Delta P=0.05 \mathrm{MPa}$

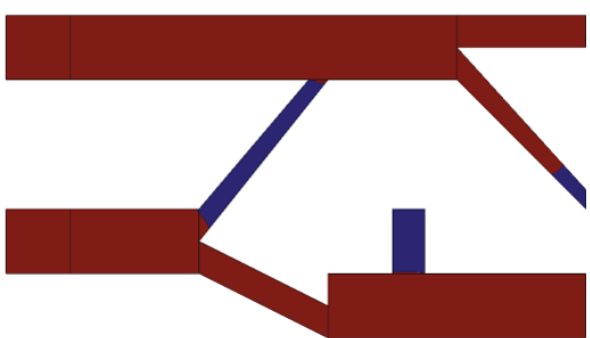

(d) $\Delta P=0.12 \mathrm{MPa}$

Fig. 14 The process of pressure threshold in the oil charging process in a pore-throat network

Different from the retained water in the lower channel, the water in the connecting channel between the upper and lower ones is theoretically movable. But, in current boundary conditions, the pressure difference between the ends of the trapped water cannot reach its threshold. In fact, if proper conditions are formed, the trapped water can also be displaced. For example, the pressure difference between $P_{1-2}$ and $P_{1-1}$ can be increased and the pressure difference between $P_{1-1}$ and $P_{2}$ is remained (at $0.12 \mathrm{MPa}$ ) in the meantime. The trapped water can be displaced when the pressure difference between $P_{1-2}$ and $P_{1-1}$ is about $0.13 \mathrm{MPa}$ (Fig. 15). This phenomenon indicates that oil charging in nano throats is much more difficult. Topology has great influence on the oil charging in nano throats. From the case, it can be found that local pressure difference controls the oil charging in a throat. Global pressure difference does not make sure of the oil charging in a specific throat. This conclusion is quite important for the research on hydrocarbon accumulation in tight reservoirs or shale.

\subsection{Discontinuous process of tight oil charging}

In this section, numerical simulations are validated and performed to reproduce the discontinuous process of tight oil charging. Some explanations are summarized below.

First, the discontinuous oil charging process here does not refer to the discontinuous process due to tectogenesis which 


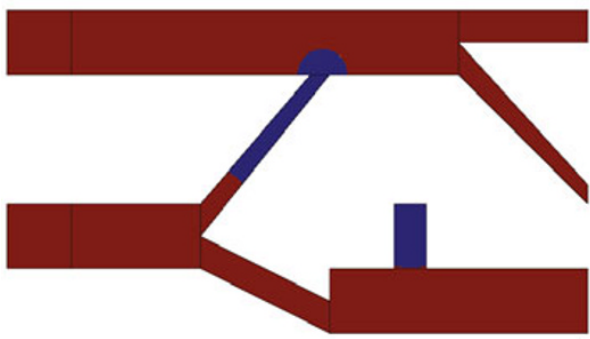

(a)

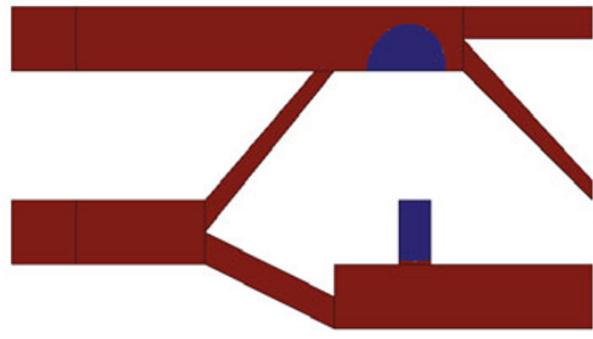

(c)

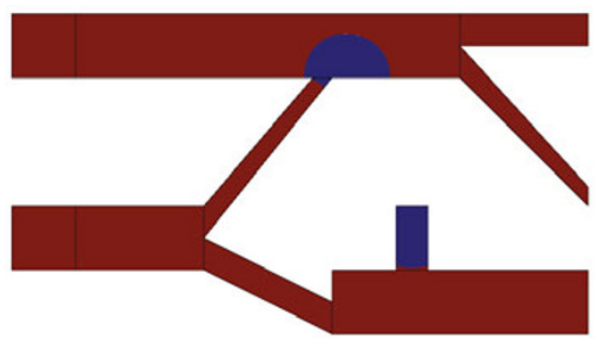

(b)

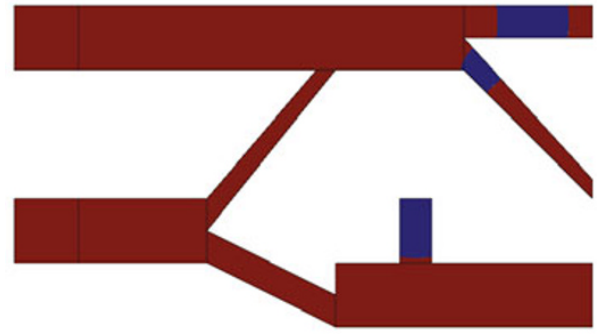

(d)

Fig. 15 Trapped water in the connecting throat is displaced

does not guarantee the continuity of hydrocarbon generation. It refers to the discontinuous process due to poor reservoir properties under continuous driving force which is usually the overpressure of hydrocarbon generation.

Second, some assumptions and applicable conditions are prerequisites to reproduce this discontinuous process. The mode of "accumulating after being tight" for tight oil is the primary premise. Hydrocarbon generation of source rock is continuous and oil is driven by overpressure into near-source reservoir. Other applicable conditions for this geological model have been discussed in Section 3.

When the overpressure of hydrocarbon generation is large enough to break through the easiest threshold, the oil begins to charge the reservoir. Then, the oil moves forward to the next threshold. In the meantime, the pressure of oil either increases or decreases. If the hydrocarbon generation rate is high enough to compensate the pressure decrease due to the volume increase when oil moves forward, the oil pressure will increase. Conversely, the pressure drops. After the oil reaches the next threshold, the oil pressure begins to increase until breaking the threshold. Then another cycle of the above process begins.

In the tight oil charging process, there are two interesting features. First, the charging is selective. The charging path is always the easiest one. Unless a local pressure difference happens to be large enough, smaller throats are very difficult to break through. The second feature of the charging process is the displacement efficiency which is highly related to topological properties of pore network. This is the basic reason resulting in the oil saturation of reservoir.

\section{Conclusions}

In this study, resistance during the tight oil charging period is analyzed and a static resistance model is proposed. Through applying incompressible Navier-Stokes equations, a phase field method and a finite element method, this model is used to reproduce the discontinuous process of tight oil displacement. From the analyses and simulations, some conclusions are summarized below.

1) Geologically, the charging of tight oil is an ultra-slow process which cannot be described by kinetic models (e.g., the family of Darcy's equation) because the kinetic resistance has only a minor effect. A proposed static model is more applicable. This model not only explains the accumulation of tight oil but also explains nonlinear behavior of percolation in a microscopic way.

2) In the static model, capillary resistance plays an important role in describing two phase flow. Dissipation resistance is another crucial component of the static model which is critical to the reduction of pressure gradient. However, the latter has not been quantitatively investigated in the current study and will be examined in future.

3) From numerical simulations, it is found that the charging process of tight oil (oil displacing water) is discontinuous. There are many pressure thresholds which should be broken through before the charging process continues. The difficulty and efficiency of tight oil displacement depend on the topological properties of the pore-throat network (e.g., size, shape, etc.). This understanding is very important for identifying "sweet spots" in tight oil reservoirs.

4) Numerical simulations also show that the tight oil displacement always follows the easiest paths. Smaller throats can only be broken through when the local pressure difference is large enough. This discovery forces relative research to pay more attention on issues of effectiveness of nano-throats.

Generally, this study abandons kinetic models usually used for petroleum development. Instead, a more applicable static model is proposed to describe the tight oil charging process. Although this model is based on some assumptions and there is still much work to improve it, the static model 
is proven of great importance for the research of tight oil accumulation.

\section{Acknowledgements}

This work was supported by the Chinese Major National Scientific and Technological Program (2011ZX05001) and Chinese Postdoctoral Fund (2013M540114). The authors would like to thank Prof. Q. L. Guo for his valuable advice.

\section{References}

AVIZO. http://www.vsg3d.com. 2014

Badakhshan A and Bakes P. The influence of temperature and surfactant concentration on interfacial tension of saline water and hydrocarbon systems in relation to enhanced oil recovery by chemical flooding. SPE Unsolicited Paper. 1990. SPE20295

Bai B, Zhu R, Wu S, et al. Multi-scale method of Nano(Micro)-CT study on microscopic pore structure of tight sandstone of Yanchang Formation, Ordos Basin. Petroleum Exploration and Development. 2013. 40(3): 354-358

Bear J. Dynamics of Fluids in Porous Media. Elsevier, New York, 1972. $764 \mathrm{pp}$

Cai B Y, Yang J T and Guo T M. Interfacial tension of hydrocarbon+water/brine systems under high pressure. Journal of Chemical \& Engineering Data. 1996. 41(3): 493-496

Chalmers G R and Bustin R M. Lower Cretaceous gas shales in northeastern British Columbia, Part I: geological controls on methane sorption capacity. Bulletin of Canadian Petroleum Geology. 2008. 56(1): 1-21

COMSOL. http://www.comsol.com/. 2014

Conti J J, Holtberg P D, Beamon J A, et al. Annual Energy Outlook 2012. US Energy Information Administration, Washington DC. 2012

Demond A H and Roberts P V. Effect of interfacial forces on twophase capillary pressure saturation relationships. Water Resources Research. 1991. 27(3): 423-437

Deng S G, Wang Y, Hu Y Y, et al. Integrated petrophysical log characterization for tight carbonate reservoir effectiveness: A case study from the Longgang area, Sichuan Basin, China. Petroleum Science. 2013. 10(3): 336-346

Golab A N, Knackstedt M A, Averdunk H, et al. 3D porosity and mineralogy characterization in tight gas sandstones. The Leading Edge. 2010. 29(12): 1476-1483

Guo Y, Liu J, Yang H, et al. Hydrocarbon accumulation mechanism of low permeable tight lithologic oil fields in the Yanchang Formation, Ordos Basin, China. Petroleum Exploration and Development. 2012. 39(4): 447-456 (in Chinese)

Jadhunandan P and Morrow N. Effect of wettability on waterflood recovery for crude-oil/brine/rock systems. SPE Reservoir Engineering. 1995. 10(1): 40-46

Jamin J. Memoire sur l'equilibre et le mouvement des liquides dans les corps poreux. Comptes Rendus Academie de Sciences de France. 1860. 50: 172

Jarvie D M, Hill R J, Ruble T E, et al. Unconventional shale-gas systems: The Mississippian Barnett Shale of north-central Texas as one model for thermogenic shale-gas assessment. AAPG Bulletin. 2007. 91(4): 475-499

Javadpour F. Nanopores and apparent permeability of gas flow in mudrocks (shales and siltstone). Journal of Canadian Petroleum Technology. 2009. 48(8): 16-21

Jia C, Zou C, Li J, et al. Assessment criteria, main types, basic features and resource prospects of the tight oil in China. Acta Petrolei Sinica. 2012. (03): 343-350 (in Chinese)

Kozeny J. Über kapillare leitung des wassers im boden. Sitzungsber.
Akad. Wiss. Wien. 1927. 136: 271-306

Kuang L, Tang Y, Lei D, et al. Formation conditions and exploration potential of tight oil in the Permian saline lacustrine dolomitic rock, Junggar Basin, NW China. Petroleum Exploration and Development. 2012. 39(6): 700-711 (in Chinese)

Liang L, Rinaldi R and Schober H. Neutron applications in earth, energy and environmental sciences. Springer-Verlag, New York, 2008. 656 pp

Liu G D, Sun M L, Zhao Z Y, et al. Characteristics and accumulation mechanism of tight sandstone gas reservoirs in the Upper Paleozoic, northern Ordos Basin, China. Petroleum Science. 2013. 10(4): 442449

Liu K, Tang X, Rashid A, et al. Petroleum Migration and Accumulation Models Revisited from a Reservoir Engineering Perspective. AAPG International Conference \& Exhibition, Singapore, 2012

Loucks R G, Reed R M, Ruppel S C, et al. Morphology, genesis, and distribution of nanometer-scale pores in siliceous mudstones of the Mississippian Barnett Shale. Journal of Sedimentary Research. 2009. 79(12): 848-861

Miller R J and Low P F. Threshold gradient for water flow in clay systems. Soil Science Society of America Journal. 1963. 27(6): 605609

Morrow N. Wettability and its effect on oil recovery. Journal of Petroleum Technology. 1990. 42(12): 1476-1484

Olsen H W. Deviations from Darcy's law in saturated clays. Soil Science Society of America Journal. 1965. 29(2): 135-140

Ross D J and Bustin M R. The importance of shale composition and pore structure upon gas storage potential of shale gas reservoirs. Marine and Petroleum Geology. 2009. 26(6): 916-927

Sakiadis B. Boundary-layer behavior on continuous solid surfaces: I. Boundary-layer equations for two-dimensional and axisymmetric flow. AIChE Journal. 1961. 7(1): 26-28

Schmutz M, Blondel A and Revil A. Saturation dependence of the quadrature conductivity of oil-bearing sands. Geophysical Research Letters. 2012. 39(3): L03402

Schnaar G and Brusseau M. Pore-scale characterization of organic immiscible-liquid morphology in natural porous media using synchrotron X-ray microtomography. Environmental Science \& Technology. 2005. 39(21): 8403-8410

Slatt R M and O'Brien N R. Pore types in the Barnett and Woodford gas shales: Contribution to understanding gas storage and migration pathways in fine-grained rocks. AAPG Bulletin. 2011. 95(12): 20172030

Sondergeld C, Ambrose R, Rai C, et al. Micro-structural studies of gas shales. SPE Unconventional Gas Conference, Pittsburg, 2010

Swartzendruber D. Modification of Darcy's law for the flow of water in soils. Soil Science. 1962a. 93(1): 22-29

Swartzendruber D. Non-Darcy flow behavior in liquid-saturated porous media. Journal of Geophysical Research. 1962b. 67(13): 5205-5213

Weszka J, Szindler M, Chwastek-Ogierman M, et al. CLSM and UVVIS researches on polyoxadiazoles thin films. Archives of Materials Science. 2012. 54(2): 53-61

Yao J, Sun H, Fan D Y, et al. Numerical simulation of gas transport mechanisms in tight shale gas reservoirs. Petroleum Science. 2013. 10(4): 528-537

Ye S J, Lu Z X and Li R. Petrophysical and capillary pressure properties of the upper Triassic Xujiahe Formation tight gas sandstones in western Sichuan,China. Petroleum Science. 2011. 8(1): 34-42

Yue P, Feng J J, Liu C, et al. A diffuse-interface method for simulating two-phase flows of complex fluids. Journal of Fluid Mechanics. 2004. 515: 293-317

Zou C, Zhang G, Yang Z, et al. Concepts, characteristics, potential and technology of unconventional hydrocarbons: On unconventional petroleum geology. Petroleum Exploration and Development. 2013a. 
40(4): 413-428

Zou C N. Unconventional Petroleum Geology. Beijing: Elsevier. 2012. $373 \mathrm{pp}$

Zou C N, Gong Y J, Tao S Z, et al. Geological characteristics and accumulation mechanisms of the "continuous" tight gas reservoirs of the Xu2 Member in the middle-south transition region, Sichuan Basin, China. Petroleum Science. 2013b. 10(2): 171-182

Zou C N, Yang Z, Cui J W, et al. Formation mechanism, geological characteristics and development strategy of nonmarine shale oil in China. Petroleum Exploration and Development. 2013c. 40(1): 1527 (in Chinese)

Zou C N, Yang Z, Tao S Z, et al. Continuous hydrocarbon accumulation over a large area as a distinguishing characteristic of unconventional petroleum: The Ordos Basin, North-Central China. Earth-Science Reviews. 2013d. 126: 358-369

Zuo Y X and Stenby E H. Calculation of Interfacial tensions of hydrocarbon-water systems under reservoir conditions. In Situ. 1998. 22(2): 157-180

\section{Appendix: Incompressible Navier-Stokes equations and two phase flow}

The Navier-Stokes equations (N-S Eqs.) describe the motion of fluid substances by applying Newton's second law. They can describe viscous flow with the assumption that the stress in the fluid is the sum of a diffusing viscous term and a pressure term. A simplification of $\mathrm{N}-\mathrm{S}$ equations can be obtained when considering an incompressible flow of a Newtonian fluid. The simplified equations include:

mass conservation equations (for incompressible flow), i.e.,

$\nabla \cdot \mathbf{u}=0$

momentum equations, i.e.,

$\rho \frac{\partial \mathbf{u}}{\partial t}+\rho(\mathbf{u} \cdot \nabla) \mathbf{u}=\nabla \cdot \mathbf{P}+\rho \mathbf{g}+\mathbf{F}$

constitutive law (Newtonian fluid), i.e.,

$\mathbf{P}=-p \mathbf{I}+\mu\left(\nabla \mathbf{u}+\nabla \mathbf{u}^{\mathbf{T}}\right)$

where, $\mathbf{u}$ is the velocity vector $(\mathrm{m} / \mathrm{s}) ; \mathbf{P}$ is the stress vector $(\mathrm{Pa}) ; \mathbf{g}$ is the gravity acceleration $\left(\mathrm{m} / \mathrm{s}^{2}\right) ; \rho$ is the fluid density $\left(\mathrm{kg} / \mathrm{m}^{3}\right) ; p$ is fluid pressure $(\mathrm{Pa}) ; \mu$ is the dynamic viscosity $(\mathrm{Pa} \cdot \mathrm{s}) ; \mathbf{F}$ is other involved forces $(\mathrm{N}) ; \nabla$ is the gradient operator; $\mathbf{I}$ is the unit matrix.

Two phase flow is commonly used in petroleum engineering. It can also be described by N-S equations with additional components. First, as a part of $\mathbf{F}$, the stress on the fluid surface $\left(\mathbf{F}_{\mathrm{st}}\right)$ should be considered in Eq. (A.2). Then, special treatment is adopted to solve the two phase incompressible N-S equations. The commonly used phase field method (PFM) introduces several instrumental variables through the following equations (Yue et al, 2004; COMSOL, 2014):

$$
\begin{aligned}
& \frac{\partial \phi}{\partial t}+\mathbf{u} \cdot \nabla \phi=\nabla \cdot \frac{\gamma \lambda}{\varepsilon^{2}} \nabla \psi \\
& \psi=-\nabla \cdot \varepsilon^{2} \nabla \phi+\left(\phi^{2}-1\right) \phi+\left(\frac{\varepsilon^{2}}{\lambda}\right) \frac{\partial f_{\mathrm{ext}}}{\partial \phi} \\
& G=\frac{\lambda}{\varepsilon^{2}} \psi
\end{aligned}
$$

where, $\phi$ is the primary dimensionless variable; $\psi$ is the secondary dimensionless variable; $\gamma$ is the fluid mobility $\left(\mathrm{m}^{3} \cdot \mathrm{s} /\right.$ $\mathrm{kg}) ; f_{\text {cxt }}$ is the external free energy $\left(\mathrm{J} / \mathrm{m}^{3}\right) ; G$ is the chemical potential $\left(\mathrm{J} / \mathrm{m}^{3}\right)$; the quantity $\lambda$ is the mixing energy density $(\mathrm{N})$ and $\varepsilon$ is a capillary width (m) that scales with the thickness of the interface. These two parameters are related to the surface tension coefficient $(\sigma)$ through the equation:

$$
\lambda=\frac{3 \varepsilon \sigma}{2 \sqrt{2}}
$$

The surface tension force for the phase field method is implemented as a body force, i.e.,

$\mathbf{F}_{\mathrm{st}}=\left(G-\frac{\partial f_{\mathrm{ext}}}{\partial \phi}\right) \nabla \phi$

To complete the above equations, boundary conditions should be introduced. The commonly adopted velocity boundary is defined as:

$\mathbf{u}= \pm U_{0} \mathbf{n}$

where, $\pm U_{0}$ is the normal inflow (outflow) velocity (m/s).

The pressure boundary condition is defined as:

$p=p_{0}$

$\left[\mu\left(\nabla \mathbf{u}+(\nabla \mathbf{u})^{\mathrm{T}}\right)\right] \cdot \mathbf{n}=0$

If wettability is considered, the wetted wall should be introduced. For the PFM, the following equations are used for describing wettability:

$\mathbf{n} \cdot \varepsilon^{2} \nabla \phi=\varepsilon^{2} \cos (\theta)|\nabla \phi|$

$\mathbf{n} \cdot \frac{\gamma \lambda}{\varepsilon^{2}} \nabla \psi=0$

where, $\theta$ is the contact angle $\left(^{\circ}\right)$. 